This article was downloaded by: [Duke University Medical Center]

On: 19 May 2015, At: 19:31

Publisher: Routledge

Informa Ltd Registered in England and Wales Registered Number: 1072954 Registered office: Mortimer House, 37-41 Mortimer Street, London W1T 3J H, UK

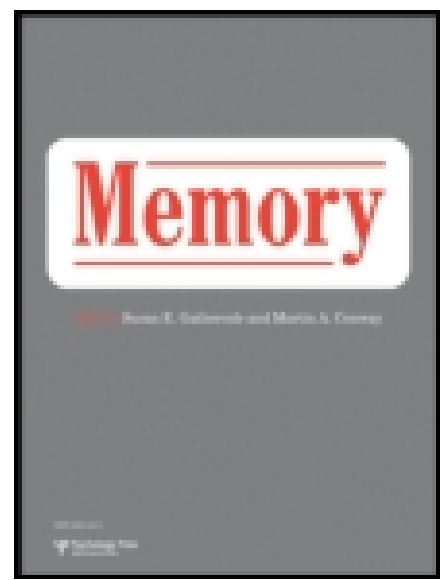

\title{
Memory
}

Publication details, including instructions for authors and subscription information: http:// www. tandfonline.com/loi/pmem20

\section{Stability in autobiographical memories}

\section{David Rubin $^{a}$, Robert Schrauf ${ }^{b} \&$ Daniel Greenberg ${ }^{c}$}

${ }^{a}$ Duke University, Durham, NC, USA

${ }^{\mathrm{b}}$ Northwestern University, Evanston, IL, USA

c Duke University, Durham, NC, USA

Published online: 22 Sep 2010.

To cite this article: David Rubin , Robert Schrauf \& Daniel Greenberg (2004) Stability in autobiographical memories, Memory, 12:6, 715-721, DOI: 10.1080/09658210344000512

To link to this article: http:// dx.doi.org/ 10.1080/09658210344000512

\section{PLEASE SCROLL DOWN FOR ARTICLE}

Taylor \& Francis makes every effort to ensure the accuracy of all the information (the "Content") contained in the publications on our platform. However, Taylor \& Francis, our agents, and our licensors make no representations or warranties whatsoever as to the accuracy, completeness, or suitability for any purpose of the Content. Any opinions and views expressed in this publication are the opinions and views of the authors, and are not the views of or endorsed by Taylor \& Francis. The accuracy of the Content should not be relied upon and should be independently verified with primary sources of information. Taylor and Francis shall not be liable for any losses, actions, claims, proceedings, demands, costs, expenses, damages, and other liabilities whatsoever or howsoever caused arising directly or indirectly in connection with, in relation to or arising out of the use of the Content.

This article may be used for research, teaching, and private study purposes. Any substantial or systematic reproduction, redistribution, reselling, loan, sub-licensing, systematic supply, or distribution in any form to anyone is expressly forbidden. Terms \& Conditions of access and use can be found at http://www.tandfonline.com/page/terms-and-conditions 


\title{
Stability in autobiographical memories
}

\author{
David C. Rubin \\ Duke University, Durham, NC, USA \\ Robert W. Schrauf \\ Northwestern University, Evanston, IL, USA \\ Daniel L. Greenberg \\ Duke University, Durham, NC, USA
}

\begin{abstract}
A total of 30 undergraduates recalled the same 20 autobiographical memories at two sessions separated by 2 weeks. At each session they dated their memories and rated them on 18 properties commonly studied in autobiographical memory experiments. Individuals showed moderate stability in their ratings on the 18 scales $(\mathrm{r} \sim .5)$, with consistency of dating being much higher $(\mathrm{r}=.96)$. There was more stability in the individuals' average rating on each scale $(\mathrm{r} \sim .8)$, even when the averages were calculated on different memories in the different sessions. The results are consistent with a constructive view of autobiographical memory, in which stable individual differences in cognitive style are important.
\end{abstract}

In this paper we investigate the stability of subjects' ratings of various aspects of their autobiographical memories. This is not a question of the accuracy or stability of the contents of the memory, but rather of the rated properties of the memory. It is possible that exactly the same factual contents will be recalled on two occasions in which a memory is rated differently on emotional reaction, importance, or the clarity of the visual image (Talarico \& Rubin, 2003). Although stability in the contents of memories has been studied (Anderson, Cohen, \& Taylor, 2000; Bluck \& Li, 2001; Thompson, Skowronski, Larsen, \& Betz, 1996) and even the relation of rated properties of memories to that stability (Conway, Collins, Gathercole, \& Anderson, 1996), less is known about the stability of rated properties of those memories. If autobiographical memories are constructed anew at each recall (Bartlett, 1932; Conway \& Pleydell-Pearce, 2000) and if the component processes involved in such constructions vary independently (Greenberg \& Rubin, 2003; Rubin, 1998), variability in the phenomenological ratings of those memories and component processes is expected. Here we obtain an estimate of the stability of these ratings.

Stability can come from two sources. First, the particular memory may require, support, or just have as an inherent property varying degrees of the processes involved (Rubin, 1995); a memory of a sunset may require more visual and less auditory imagery than a memory of a concert. Second, the individual recalling may routinely favour one process over another, a form of cognitive style. For example, an individual may consistently rate one particular memory as highly visual either because that memory, in contrast to his or her other memories, is very visual or because all of that individual's memories are very visual. Both sources of stability can be measured.

Correspondence should be addressed to David C. Rubin, Psychological and Brain Sciences, Duke University, Box 90086, Durham NC 27707-0086, USA. Email: david.rubin@duke.edu

We wish to thank NIA grant RO1 AG16340 for support. This paper was written in part when DCR was a Visiting Professor at the Psychology Department, University of Aarhus, Denmark. 
To examine stability inherent to particular memories, we correlate within individuals to assess the degree to which ratings on individual memories change. As will be shown, the overall tendency for an individual to rate all memories high or low on a particular scale, or to rate all memories more highly on a particular day, has no effect on the stability because the individual's means are subtracted out in such correlations. To examine stability caused by the consistent cognitive style of individuals, we correlate the average value on each rating scale across individuals to assess the degree to which these average ratings change.

\section{PROPERTIES OF AUTOBIOGRAPHICAL MEMORIES TO BE MEASURED}

Psychologists studying autobiographical memory have tended to have subjects rate the same properties of memories (Johnson, Foley, Suengas, \& Raye, 1988; Rubin, Groth, \& Goldsmith, 1984; Rubin \& Schulkind, 1997; Rubin, Schrauf, \& Greenberg, 2003b; Schrauf \& Rubin, 2000). Some of the properties, such as visual imagery, can be seen as measures of component processes used in constructing the autobiographical memory, while others, such as a sense of recollection, can be viewed as metacognitive judgements (Greenberg \& Rubin, 2003; Rubin et al., 2003b). Here we try to sample these properties in a reasonable way. The full set of questions is given in the Appendix. Each question is a proxy for one or more theoretical ideas. A discussion of the theoretical motivation for these variables can be found in Rubin et al. (2003b) and Rubin, Burt, and Fifield (2003a).

\section{WITHIN-SUBJECT AND BETWEEN- SUBJECTS ANALYSES OF STABILITY}

All 30 subjects recalled and rated the same 20 autobiographical memories on two occasions separated by 2 weeks. For each rating scale, the values from the first session are correlated with the values from the second session. We measure stability in three ways. The first way considers each of the 600 memories as a unit. This baseline measure confounds within-subject and betweensubjects stability (Wright, 1998). The second way is within subject. For each rating scale, we corre- late ratings from the two sessions for each of the 30 subjects separately across their 20 memories. For ease of presentation, we report the average of these 30 correlations. The third way is between subjects. For each rating scale, we average each subject's 20 memories at each session to produce a mean value for each session. We then correlate these pairs of means, one pair for each subject, across the 30 subjects. The within-subject correlations measure how well each individual reproduces their ratings of their own individual memories. The between-subjects correlations measure the subjects' overall tendency to rate all their memories as high or low on both sessions.

Psychologists have long argued that combining nomethetic, or within-subject, and idiographic, or between-subjects, research is important (Cronbach, 1957; Underwood, 1975). Here, we do both within the same data set by using parallel correlational techniques. As Cronbach (1957) noted, nomothetic research and idiographic research each use as data what the other approach dismisses as error variance. In Cattell's (1952, p. 502) terms, the within and between correlations "have no necessary mathematical relation". Correlations are the same whether they are calculated on raw scores or on linear transformations of those raw scores, such as $z$-scores. In particular, correlation coefficients do not change if the mean of each variable is subtracted from each value of that variable. Thus, when we calculate correlations within an individual, the mean value of that individual on each variable does not affect the results and can even be removed from the data set. But it is exactly the set of these mean values-and only these mean values - that we use for the individual differences, between-subjects, analyses. Therefore, the within-subject and between-subjects analyses are each based on information the other analysis does not use. Here, we keep these analyses separate, though they could be combined (Wright, 1998).

\section{EXPERIMENT 1}

\section{Method}

To obtain memories that would be distinctive enough that the same memory would be able to be recalled after 2 weeks, we asked undergraduates to nominate and label 20 memories without any other cues or restrictions. We chose a 2 week interval between sessions because (1) it seemed 
long enough to allow changes in the way a memory would be constructed and rated if such changes were to occur, (2) subjects would not be able to remember their first set of ratings over 2 weeks, and (3) 2 weeks was short enough that the chance of recalling a different event given the same selfgenerated cue was small. The stability of the dating of the memories supports our last assumption.

Subjects. A total of 31 Duke University undergraduates who were native speakers of English or who had spoken English for at least 8 years participated. One subject was eliminated because of a failure to produce ratings to three memories. The average age of the remaining 30 subjects was 18.38 ( $\mathrm{SD}=0.73$, range 17 to 20$) ; 23$ were female.

Materials and procedure. Each subject was given a sheet of paper with instructions and numbered blank lines. The instructions included: "On each of the 20 lines below, please write a brief description, which need be intelligible only to you, of an event for which you have an autobiographical memory.... The description should be specific enough to cue one and only one event in your life." Subjects were then given a booklet consisting of a cover page with instructions, a double-sided sample page containing 19 questions about a sample event (the first class you went to last week), a dividing page, and then 20 more double-sided pages, each of which contained a number from 1 to 20 to correspond to the events listed with the 19 questions referring to the memory it elicited. The instructions began: "In this study we are trying to find out about the basic properties of autobiographical memories. For each description we will ask you to recall the your memory, to think about it for awhile, and then to answer questions about the memory. There are no correct answers; we are just trying to document the kind of memories people have." Each question was discussed with regard to the sample event before subjects continued at their own pace with the rest of the booklet.

The subjects were tested in groups. They were informed when they agreed to participate that there were two sessions 2 weeks apart and that both were required, but they were not told that they would have to rate the same memories twice. After the instructions and sample event of the first session, the experiment was self-paced. Each session took between 45 and 75 minutes to complete.

\section{Results}

Table 1 presents the mean of each rating scale from session 1 and how it differs in session 2 . The differences in these means are small, between -0.08 and 0.32 on a 7-point scale, so there is no major drift in the means from session to session, but there is considerable variability in ratings. Table 2 shows the correlations between sessions 1 and 2. Column 2 shows correlations for all 600 memories. For example, for reliving, ratings of reliving for all 600 memories from session 1 were correlated with their ratings from session 2. Column 3 shows the average within-subject correlations. For example, for reliving, these were computed as follows. Subject 1's ratings of reliving for the 20 memories recalled at session 1 were correlated with his or her ratings of reliving for those 20 memories recalled again at session 2 . This was done for each subject, and then the average of those session 1 -session 2 correlations was taken over all 30 subjects. Column 4 shows the betweensubjects correlations. For example, for reliving, these were computed as follows. Each subject's mean rating of reliving for the 20 memories at session 1 was calculated, and then their mean rating of reliving for session 2 . These pairs of 30 means, one pair for each subject, were then correlated. The correlations of Table 2 show an interesting pattern; the average correlations within subject are lower than the correlations between subjects. Again, taking reliving as an example, the average correlation within subject was .47. Thus individual subjects were fairly stable on rating individual memories on reliving; the ratings on one session account for about a quarter of the variance of the ratings on the other session. When we compare the stability of the mean ratings across sessions in the between-subjects correlations, they are even more stable. For example, the between-subjects stability of reliving is .75 , which accounts for about twice as much variance as the within-subject correlations.

In rating the same 20 autobiographical memories on two occasions separated by 2 weeks, there is more stability in the mean ratings of the subjects than in the ratings of individual subjects on their individual memories. One reason for this could be that the same memories are being rated and by averaging before calculating correlation we remove random variation. To rule this out, the last column of Table 2 shows the stability between subjects when we correlated the even-numbered memories from session 1 with the odd-numbered 
TABLE 1

Means and standard deviations of all scales

\begin{tabular}{|c|c|c|c|c|c|c|}
\hline \multirow[b]{2}{*}{ Variable } & \multicolumn{3}{|c|}{ Session 1} & \multicolumn{3}{|c|}{$\begin{array}{l}\text { Difference } \\
\text { in session }\end{array}$} \\
\hline & Mean & $\begin{array}{l}S D \\
b / t\end{array}$ & $\begin{array}{l}S D \\
w / i\end{array}$ & Mean & $\begin{array}{l}S D \\
b / t\end{array}$ & $\begin{array}{l}S D \\
w / i\end{array}$ \\
\hline Reliving & 4.76 & 0.86 & 1.34 & 0.08 & 0.78 & 1.28 \\
\hline Back in Time & 4.62 & 1.20 & 1.38 & 0.27 & 0.71 & 1.30 \\
\hline Remember/Know & 5.99 & 0.76 & 0.96 & 0.07 & 0.34 & 0.94 \\
\hline Real/Imagine & 6.00 & 0.75 & 0.88 & 0.12 & 0.47 & 0.89 \\
\hline Persuade & 2.87 & 0.64 & 1.32 & 0.00 & 0.43 & 1.22 \\
\hline See & 5.95 & 0.68 & 0.90 & 0.12 & 0.34 & 0.96 \\
\hline Setting & 6.35 & 0.61 & 0.62 & 0.21 & 0.48 & 0.65 \\
\hline Spatial & 5.88 & 0.91 & 0.90 & 0.11 & 0.56 & 0.88 \\
\hline Hear & 3.96 & 1.16 & 1.60 & -0.07 & 0.58 & 1.49 \\
\hline Talk & 4.58 & 1.03 & 1.65 & 0.16 & 0.59 & 1.45 \\
\hline In Words & 2.76 & 1.59 & 0.95 & 0.12 & 0.35 & 1.00 \\
\hline Story & 4.25 & 0.89 & 1.50 & 0.32 & 0.73 & 1.48 \\
\hline Fragmented & 3.69 & 0.98 & 1.49 & -0.01 & 0.51 & 1.43 \\
\hline General & 2.24 & 1.17 & 0.97 & 0.28 & 0.64 & 1.02 \\
\hline Emotions & 4.67 & 0.97 & 1.48 & 0.17 & 0.63 & 1.32 \\
\hline Importance & 3.90 & 1.02 & 1.77 & 0.16 & 0.46 & 1.18 \\
\hline Rehearsal & 3.81 & 0.93 & 1.39 & -0.08 & 0.45 & 1.09 \\
\hline Specific & 0.76 & 0.16 & 0.37 & -0.01 & 0.16 & 0.26 \\
\hline Merged/Extended & 1.45 & 0.36 & 0.32 & 0.00 & 0.16 & 0.30 \\
\hline Age of Memory & 1092 & 635 & 1192 & -1.88 & 58 & 192 \\
\hline
\end{tabular}

$\mathrm{b} / \mathrm{t}=$ between subject. $\mathrm{w} / \mathrm{i}=$ within subject. The standard deviations in the within column are the average of the standard deviations of the 30 subjects.

memories from session 2 and vice versa, averaged these (geometrically), and then used the Spearman-Brown Prophesy Formula to correct for there only being half as many memories in each estimate. The stability in subject means over session using different memories in each session is about as large as the stability when the same memories are used, indicating that what is stable across sessions is the cognitive style of each subject. For example, people who show a high level of reliving on one session do so on both sessions independent of the particular memories recalled. One statistical issue should be noted in interpreting these results; they depend on the number of memories rated. The between-subjects stability is almost as high as the reliability of the scales. As we know that the reliability of a scale changes with the number of items in it, the between-subjects stability correlations would also change with the number of memories rated.

If only one memory per subject were sampled, the stability in ratings would be a result of the stable cognitive style of the subject and the particular memory recalled. To see how stable the recalls of individual memories would be, we calculated correlations over the 30 subjects' responses to each of their 20 memories separately. That is, we took just the first memory of each subject and looked at how stable its ratings were over the 30 subjects. Then we did the second memory, and so forth, for all 20 memories. Except for two variables, the average of these values over all 20 memories was always within \pm .02 of the allmemories correlations shown in Table 2 .

Two variables show a deviation from this overall within-subject versus between-subjects pattern. The dating of the memories, as measured by age of memory, is very stable both within subject and between subjects, and the correlation falls considerably when the means of different memories are used from the two sessions. The difference between the between and within stability for the in words variable is much greater than in the other variables. It has the highest stability of any of the 7-point rating scales between subjects and one of the lowest within subject. Thus, it may be much more of a cognitive style variable than our other ratings. 
TABLE 2

Stability of measures over sessions

\begin{tabular}{|c|c|c|c|c|c|c|}
\hline \multirow[b]{3}{*}{ Variable } & \multirow{3}{*}{$\begin{array}{c}\begin{array}{c}\text { All } \\
\text { memories }\end{array} \\
r_{1,2}\end{array}$} & & & \multicolumn{3}{|c|}{ Between subject } \\
\hline & & \multicolumn{2}{|c|}{$\begin{array}{c}\text { Average } \\
\text { within subject }\end{array}$} & \multicolumn{2}{|c|}{ All } & \multirow{2}{*}{$\frac{\text { Odd/Even }}{r_{1,2}}$} \\
\hline & & $r_{1,2}$ & $\mathrm{SD}_{\mathrm{r}}$ & $r_{1,2}$ & $\alpha$ & \\
\hline Reliving & .55 & .47 & .26 & .75 & .91 & .83 \\
\hline Back in Time & .65 & .43 & .32 & .86 & .95 & .89 \\
\hline Remember/Know & .60 & .45 & .26 & .91 & .91 & .91 \\
\hline Real/Imagine & .64 & .39 & .30 & .89 & .94 & .92 \\
\hline Persuade & .56 & .51 & .23 & .78 & .81 & .82 \\
\hline See & .56 & .39 & .24 & .90 & .92 & .90 \\
\hline Setting & .62 & .44 & .26 & .83 & .94 & .87 \\
\hline Spatial & .67 & .43 & .29 & .85 & .95 & .88 \\
\hline Hear & .66 & .52 & .20 & .90 & .92 & .88 \\
\hline Talk & .66 & .56 & .18 & .88 & .89 & .87 \\
\hline In Words & .78 & .37 & .27 & .97 & .98 & .98 \\
\hline Story & .49 & .44 & .31 & .70 & .88 & .77 \\
\hline Fragmented & .60 & .47 & .23 & .86 & .89 & .88 \\
\hline General & .60 & .31 & .29 & .84 & .95 & .89 \\
\hline Emotions & .64 & .54 & .20 & .83 & .90 & .84 \\
\hline Importance & .78 & .73 & .20 & .90 & .87 & .86 \\
\hline Rehearsal & .73 & .64 & .21 & .89 & .90 & .87 \\
\hline Once/Many & .64 & .70 & .32 & .69 & .77 & .64 \\
\hline Merged/Extended & .66 & .42 & .62 & .91 & - & .74 \\
\hline Age of Memory & .98 & .96 & .16 & .99 & .80 & .86 \\
\hline
\end{tabular}

$\alpha$ is Cronbach's Alpha.

\section{Discussion}

Although the methodological distinction between measurements made within and among subjects is common and well developed in statistical analyses, the conceptual distinction has often been ignored, with different researchers favouring one or the other type of analysis. This is not a new problem (Cronbach, 1957; Underwood, 1975). Here we did correlations totally within individuals to see the relation among variables within each individual. We also used the same data to do between-subjects analyses. There is no necessary reason to expect similar findings from the two levels of analysis, they are truly independent of each other. In doing this, we have demonstrated that stability in ratings can be measured both within subject and between subjects and that doing so results in answers to different questions.

We have shown that there is considerable stability in the repeated ratings of the same memory. Within an individual who is rating the same memories at a 2 week interval, about a quarter of the variance in one session's ratings can be explained by the other session's ratings. If the analysis is done over the mean ratings of 20 memories from each individual at each session, about half of the variance can be explained even if different memories are sampled from the two sessions. Most rating scales follow this pattern. Two exceptions are the dating of the memory, which, as expected, is more stable (Thompson et al., 1996) and the rating of whether the memory came in words, which is much less stable within subject but much more stable between subjects. Researchers who have studied the dating of autobiographical memories have claimed that the date of a memory is not a property of the memory in the same sense that visual imagery or emotional tone is. Rather the date is inferred from information internal and external to the memory (Brewer, 1996; Thompson et al., 1996). The other scale that deviated from the overall pattern was whether the memory came in words. The ratings of whether a memory comes in words appears to reflect individual differences in cognitive style more than other variables.

Why is the within-subject stability so much lower than the between-subjects stability? There are at least two reasons. First, if we examine the 
overall stability of the ratings calculated using the individual memories as the units of analysis, as is done in the first column of Table 2, the correlations are usually much higher than the average within-subject correlations. This is because the means calculated over all memories (and therefore all subjects) are used in calculating the correlations, whereas in the within-subject correlations the means of each individual are used. Individuals have different and fairly stable means on the various rating scales, which they stay fairly close to (as shown in Table 1), and this source of stability is removed from the within-subject correlations. The second reason is that the betweensubjects correlations are calculated on the average of 20 memories, and averages of similar measurements are just more stable than the individual measurements on which they are based. But even if we use only one memory per subject for the between-subjects correlations, the between-subjects stability would be higher. Much of the stability in the ratings made here are due to stable tendencies in the way our subjects rate all of their memories.

We have only begun to examine the question of stability. Because we have not measured the stability of details of the contents of the memory (Anderson et al., 2000; Conway et al., 1996; Talarico \& Rubin, 2003), any lack of stability does not suggest inaccuracy; a memory may just be more vivid, or coherent, or have more auditory imagery on one occasion than another. Further investigations should combine rating scales of the properties of memories with measurements of their contents, vary the interval between the sessions and between the event and the sessions (Talarico \& Rubin, 2003), vary the goals of the subjects at the two sessions (i.e., recall as accurately as you can versus recall as vividly as you can), ask whether some individuals are consistently more stable on their ratings and why, and so forth, to see how, at both the level of the individual memory and the individual subject, the recall of an event varies from time to time.

Manuscript received 20 November 2002 Manuscript accepted 3 July 2003 PrEview proof published online 7 January 2004

\section{REFERENCES}

Anderson, S. J., Cohen, G., \& Taylor, S. (2000). Rewriting the past: Some factors affecting the variability of personal memories. Applied Cognitive Psychology, 14, 435-454.
Bartlett, F. C. (1932). Remembering: A study in experimental and social psychology. London: Cambridge University Press.

Bluck, S., \& Li, K. Z. H. (2001). Predicting memory completeness and accuracy: Emotion and exposure in repeated autobiographical recall. Applied Cognitive Psychology, 15, 145-158.

Brewer, W. F. (1996). What is recollective memory? In D. C. Rubin (Ed.), Remembering our past: Studies in autobiographical memory (pp. 19-66). Cambridge: Cambridge University Press.

Cattell, R. B. (1952). The three basic factor-analytic research designs-their interrelations and derivatives. Psychological Bulletin, 49, 499-520.

Conway, M. A., Collins, A. F., Gathercole, S. E., \& Anderson, S. J. (1996). Recollection of true and false autobiographical memories. Journal of Experimental Psychology: General, 125, 69-95.

Conway, M. A., \& Pleydell-Pearce, C. W. (2000). The construction of autobiographical memories in the self-memory system. Psychological Review, 107, 261-268.

Cronbach, L. J. (1957). Two disciplines of scientific psychology. American Psychologist, 12, 671-684.

Greenberg, D. L., \& Rubin, D. C. (2003) The neuropsychology of autobiographical memory. Cortex, 39, 687-728.

Johnson, M. K., Foley, M. A., Suengas, A. G., \& Raye, C. L. (1988). Phenomenal characteristics of memories for perceived and imagined autobiographical events. Journal of Experimental Psychology: General, 117, 371-376.

Rubin, D. C. (1995). Memory in oral traditions: The cognitive psychology of epic, ballads, and countingout rhymes. New York: Oxford University Press.

Rubin, D. C. (1998). Beginnings of a theory of autobiographical remembering. In C. P. Thompson, D. J. Herrmann, D. Bruce, J. D. Reed, D. G. Payne, M. P. Toglia (Eds.), Autobiographical memory: Theoretical and applied perspectives (pp. 47-67). Mahwah, NJ: Lawrence Erlbaum Associates Inc.

Rubin, D. C., Burt, C. D. B., \& Fifield, S. J. (2003a). Experimental manipulations of the phenomenology of memory. Memory \& Cognition, 31, 877-886.

Rubin, D. C., Groth, L., \& Goldsmith, D. (1984). Olfactory cuing of autobiographical memory. American Journal of Psychology, 97, 493-507.

Rubin, D. C., Schrauf, R. W., \& Greenberg, D. L. (2003b). Belief and recollection of autobiographical memories. Memory \& Cognition, 31, 887-901.

Rubin, D. C., \& Schulkind, M. D. (1997). Distribution of important and word-cued autobiographical memories in 20-, 35-, and 70 year-old adults. Psychology and Aging, 12, 524-535.

Schrauf, R. W., \& Rubin, D. C. (2000). Identification of internal languages of retrieval: The bilingual encoding of memories for the personal past. Memory \& Cognition, 28, 616-623.

Talarico, J. M., \& Rubin, D. C. (2003). Confidence, not consistency, characterizes flashbulb memories. Psychological Science, 14, 455-461.

Thompson, C. P., Skowronski, J. S., Larsen, S. F., \& Betz, A. L. (1996). Autobiographical memory: Remembering what and remembering when. Hillsdale, NJ: Lawrence Erlbaum Associates Inc. 
Underwood, B. J. (1975). Individual differences as a crucible in theory construction. American Psychologist, 30, 128-134.

Wright, D. B. (1998). Modelling clustered data in autobiographical memory research: The multilevel approach. Applied Cognitive Psychology, 12, 339-357.

\section{APPENDIX QUESTIONS USED}

The words underlined here were underlined and set in bold in the booklet to ensure that the high end of the scale would be noted. For Questions 1 through 7, the scales range from 1 (not at all), to 3 (vaguely), to 5 (distinctly), to 7 (as clearly as if it were happening right now). For Questions 8 through 13 and 15 , the scales range from 1 (not at all), to 3 (vaguely), to 5 (distinctly), to 7 (completely). The remaining questions have unique scales.

1. As I remember the event, I feel as though I am reliving the original event.

2. As I remember the event, I can hear it in my mind.

3. As I remember the event, I can see it in my mind.

4. As I remember the event, I or other people are talking.

5. As I remember the event, I know its spatial layout.

6. As I remember the event, I can feel now the emotions that I felt then.

7. As I remember the event, I can recall the setting where it occurred.

8. Sometimes people now something happened to them without being able to actually remember it. As I think about the event, I can actually remember it rather than just knowing that it happened.

9. My memory is fragmented into details with missing bits.

10. As I remember the event, it comes to me in words.

11. As I remember the event, I feel that I travel back to the time when it happened, that I am a subject in it again, rather than an outside observer tied to the present.

12. As I remember the event, it comes to me in words or in pictures as a coherent story or episode and not as an isolated fact, observation, or scene.
13. This memory is significant for my life because it imparts an important message for me or represents an anchor, critical juncture, or a turning point.

14. I believe the event in my memory really occurred in the way I remember it and that I have not imagined or fabricated anything that did not occur. (Scale: $1=100 \%$ imaginary; $7=100 \%$ real)

15. My memory has no details specific to my life. It is based on general knowledge that I would expect most people to have.

16. Since it happened, I have thought or talked about this event. (Scale: $1=$ not at all; $7=$ as often as any event in my life)

17. If another witness to the event, who you generally trusted, existed and told you a very different account of the event to what extent could you be persuaded that your memory was wrong. (Scale: $1=$ not at all; $3=$ in some details; $5=$ in some main points; 7 = completely)

18. To the best of your knowledge, is the memory of an event that occurred once at one particular time and place, a summary or merging of many similar or related events, or for events that occurred over a fairly continuous extended period of time lasting more than a day. (Scale: $1=\overline{\text { once; } 2=}$ merging; 3 = extended)

Responses to this question were recoded to produce two scales. Once/many had a value of 1 if the subject judged the memory to take place within a single day and 0 if it took longer. Merge had a value of 1 if the event lasted longer than a day and was extended in a fairly continuous manner over a period of time and 2 if it was the merging of many discrete events.

19. Please date the memory (month/day/year) as accurately as you can. Please fill in a month, day, and year even if you must estimate. If the memory extended over a period of time, report the approximate middle of the period. (Scored as retention interval in days) 